\title{
Basic Vapor Exposure for Tuning the Charge State Distribution of Proteins in Negative Electrospray lonization: Elucidation of Mechanisms by Fluorescence Spectroscopy
}

\author{
Marion Girod, ${ }^{1}$ Rodolphe Antoine, ${ }^{1}$ Philippe Dugourd, ${ }^{1}$ Craig Love, ${ }^{2}$ Alex Mordehai, ${ }^{2}$ \\ George Stafford ${ }^{2}$
}

${ }^{1}$ Laboratoire de Spectrométrie Ionique et Moléculaire Villeurbanne, France, Université de Lyon, 69622 Lyon, France, Université Lyon 1, Villeurbanne CNRS, UMR5579

${ }^{2}$ Agilent Technologies, 5301 Stevens Creek Boulevard, Santa Clara, CA 95051 USA

${ }^{3}$ Present Address: CNRS and Université Lyon 1, Institut des Sciences Analytiques, UMR 5280, 43 Bd du 11 Novembre 1918, Villeurbanne cedex, 69622 France

\begin{abstract}
Manipulation for simplifying or increasing the observed charge state distributions of proteins can be highly desirable in mass spectrometry experiments. In the present work, we implemented a vapor introduction technique to an Agilent Jet Stream ESI (Agilent Technologies, Santa Clara, CA, USA) source. An apparatus was designed to allow for the enrichment of the nitrogen sheath gas with basic vapors. An optical setup, using laser-induced fluorescence and a $\mathrm{pH}$-chromic dye, permits the $\mathrm{pH}$ profiling of the droplets as they evaporate in the electrospray plume. Mechanisms of $\mathrm{pH}$ droplet modification and its effect on the protein charging phenomenon are elucidated. An important finding is that the enrichment with basic vapors of the nitrogen sheath gas, which surrounds the nebulizer spray, leads to an increase in the spray current. This is attributed to an increase in the electrical conductivity of water-amine enriched solvent at the tip exit. Here, the increased current results in a generation of additional electrolytically produced $\mathrm{OH}^{-}$ions and a corresponding increase in the $\mathrm{pH}$ at the tip exit. Along the electrospray plume, the $\mathrm{pH}$ of the droplets increases due to both droplet evaporation and exposure to basic vapors from the seeded sheath gas. The $\mathrm{pH}$ evolution in the ESI plume obtained using pure and basic seeded sheath gas was correlated with the evolution of the charge state distribution observed in mass spectra of proteins, in the negative ion mode. Taking advantage of the Agilent Jet Stream source geometry, similar protein charge state distributions and ion intensities obtained with basic initial solutions, can be obtained using native solution conditions by seeding the heated sheath gas with basic vapors.
\end{abstract}

Key words: Electrospray ionization, pH, Mechanisms, Protein, Charge state distributions, Fluorescence spectroscopy

Electronic supplementary material The online version of this article (doi:10.1007/s13361-012-0375-1) contains supplementary material, which is available to authorized users.

Correspondence to: Rodolphe Antoine; e-mail: rantoine@lasim.univ-lyon1.fr

\section{Introduction}

C lectrospray ion sources efficiently produce gas-phase

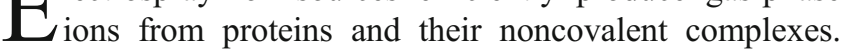
One of the interesting phenomena associated with electro- 
spray ionization (ESI) [1] is that proteins are observed as multiple charge state ions [2]. The collection of charge states observed by ESI mass spectrometry (ESI-MS) for a particular molecule under a given set of experimental conditions is referred to as the charge state distribution (CSD). The charge state distributions of macromolecules can be influenced by many factors, such as the extent of analyte charging, including analyte conformation $[3,4]$, solution $\mathrm{pH}$ [5], competition for charge between the analyte and other species [5-10], instrumental parameters and desolvation conditions [11], solvent and analyte basicity [8, 12], and solvent surface tension [13]. Many of these factors are interrelated. For example, changes in the solution $\mathrm{pH}$, solvent, and heating conditions can affect the conformation of a protein, thereby shifting the observed CSD.

According to the context of the measurement, manipulation for simplifying or increasing the observed CSD can be highly desirable in a mass spectrometry experiment. For example, shifting the mass-to-charge ratio $(\mathrm{m} / \mathrm{z})$ of high molecular weight proteins to ranges that are within the limits of conventional mass analyzers makes them more amenable to analysis by top-down tandem mass spectrometry $[14,15]$. It may also be interesting to shift the CSD to a single charge state to avoid dilution of the analyte on many peaks or to simplify the spectrum [16]. This raises the pivotal question of understanding and possibly controlling the charge distribution of gas phase proteins produced in ESI-MS.

Several strategies have been reported in the literature in an effort to control the observed charge state distributions. One strategy is to manipulate solution conditions, such as solvent composition and $\mathrm{pH}$ [10]. Other approaches involve the addition of "super-charging" [13, 17-21] or redox agents [22]. Methods for the control of the charge state distribution by gas-phase proton transfer via ion/ion [23, 24] and ion/ molecular [25-27] reactions have also been reported, which eliminates many of the drawbacks of adding external reagents, such as poor ESI response. Other methods that involve phenomena associated with charge droplets such as extractive electrospray ionization [28, 29], fused dropletelectrospray ionization, and inductive electrospray [30] have also been developed recently.

In addition, Schnier and coworkers [31] and, recently, McLuckey and coworkers [32-34] reported a simple vapor introduction technique in the atmosphere/vacuum interface region of an ESI source. Using this setup, the average charge state of ions derived from a protein was increased in the positive polarity via the introduction of acidic vapors and increased in the negative polarity via the introduction of basic vapors. Comparison of mass spectra collected for solutions at different $\mathrm{pH}$, as well as the dependence of the $\mathrm{CSD}$ on the pKa of the leaked-in vapor, suggested that the charging phenomenon was mainly attributable to a modification of the $\mathrm{pH}$ of the droplets along the plume [33, 34]. However, no measurement of the $\mathrm{pH}$ changes along the spray plume was performed when the electrospray droplets were exposed to acidic or basic vapors.
Spectroscopic measurements can help to investigate the chemical and physical properties of electrospray droplets within the spray stream [7]. In the pioneering work by Zhou et al. $[35,36]$, the change in $\mathrm{pH}$ was studied along the electrospray plume, using a $\mathrm{pH}$-chromic dye and laserinduced fluorescence (LIF) measurements. The same strategy was recently used by Wang and Zenobi to probe the solvent polarity evolution along an electrospray plume [37]. Based on the current state-of-the-art of imaging of sprays, we recently proposed a new experimental approach that combines simultaneous in situ measurements by optical methods with mass spectrometry measurements [38, 39]. In particular, this coupling allows us to measure simultaneous mass spectra and $\mathrm{pH}$ profiles to study the relation between the charge states of peptide anions in mass spectra and $\mathrm{pH}$ changes in the spray plume [38]. In the present paper, we implement the vapor introduction technique to an Agilent Jet Stream ESI source using a specially designed apparatus to allow the enrichment of the nitrogen sheath gas with basic vapors. The previously described optical setup permits profiling of the $\mathrm{pH}$ of the droplets as they evaporate in the electrospray plume with or without the addition of basic vapors. Mass spectra are recorded simultaneously. The correlation of $\mathrm{pH}$ evolution at the exit of the Taylor cone and along the ESI plume using pure and basic seeded sheath gas with the charge state distribution (CSD) of proteins observed in negative ion mass spectra is reported.

\section{Experimental}

\section{Optical Instrumentation}

The experimental setup profiling the spray plume consists of an excitation laser and an optical detection system mounted on a moving stage. It is coupled to a single quadrupole mass spectrometer equipped with an electrospray ionization source (Figure 1). A $532 \mathrm{~nm} \mathrm{CW}$ laser emitting on a single longitudinal mode was used. The output power of the laser is $300 \mathrm{~mW}$ and its beam diameter is $0.3 \mathrm{~mm}$ (divergence 1.2 $\mathrm{mrad}$ ). Details of the fluorescence instrumentation is described elsewhere [38]. Briefly, the laser beam is focused into the spray and the fluorescence is collected by an objective used in an epifluoresence configuration with a working distance of $89 \mathrm{~mm}$ (Figure 1). Fluorescence spectra of fluorescent dyes from the ESI plume were recorded using an ultra-compact spectrophotometer. The spectrometer is directly fixed to the objective and cooled to $5{ }^{\circ} \mathrm{C}$.

The excitation laser, the spectrophotometer and all the optics (objectives, mirrors, filters, and fluorescence cube) are mounted onto a moving stage. Three step-by-step motors allow independent $\mathrm{X}, \mathrm{Y}$, and $\mathrm{Z}$ movement and scanning of the ESI plume with a precision that is better than $4 \mu \mathrm{m}$. We use a custom software application to control the moving stage and data acquisition. This in-house software allows piloting of the moving stage along the $\mathrm{X}, \mathrm{Y}$, and $\mathrm{Z}$ axes for specific positioning as well as automatic step-by-step scans 


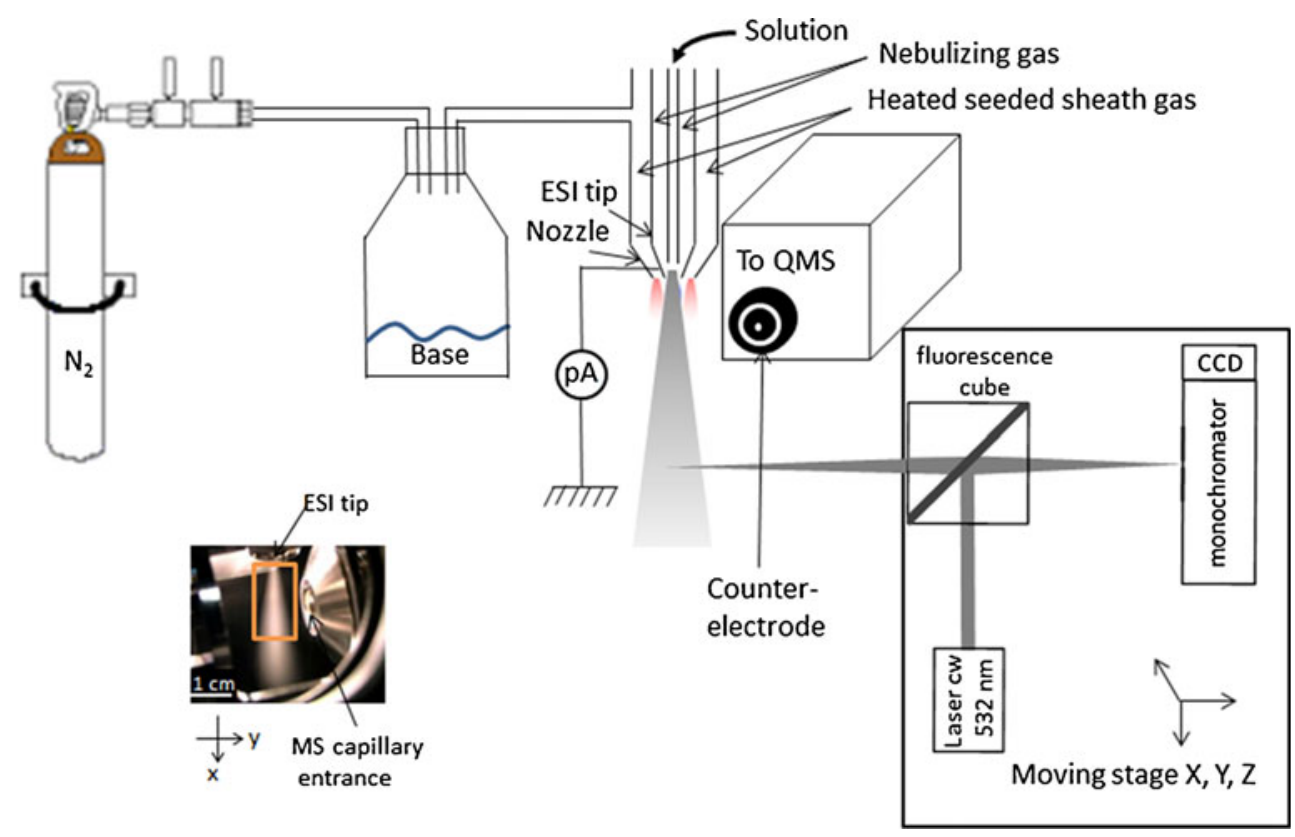

Figure 1. Schematic of the experimental setup used to probe fluorescence in the Agilent jet stream plume with seeded sheath gas. Inset: Picture of the illuminated ESI plume. The rectangle corresponds to the scanned area of the plume for fluorescent measurements $(X=0-20 \mathrm{~mm}, Y=0-11 \mathrm{~mm}$, and $Z$ was set at the entrance of the capillary)

for $3 \mathrm{D}$ profiling. In the profiling mode, the spectrophotometer is synchronized with the motors and fluorescence spectra are recorded at each step. The spatial resolution (on the $\mathrm{X}$ and $\mathrm{Y}$ axes) for the profiling experiments is $200 \mu \mathrm{m}$ [38]. The limit of detection (LOD) for fluorescence measurements was estimated at $10^{-11} \mathrm{M}$ for Rhodamine $6 \mathrm{G}$ dye [38]. The dynamic range of detection between the LOD and the highest possible dye concentration for which fluorescence spectra are not saturated was estimated to be $10^{4}$.

\section{ESI and Mass Spectrometry}

Experiments were performed on a Single Quad 6100 equipped with an Agilent Jet Stream (AJS) ESI source. The ESI tip of the AJS source has variable nebulizing pressure and is orthogonal to the MS capillary entrance. The ESI tip is flush with an outer concentric metal nozzle that delivers heated sheath gas (Figure 1). The sheath gas, which is heated up to $400{ }^{\circ} \mathrm{C}$ using a resistive heater and heat exchanger, improves ion focusing and desolvation for greater signal and reduced noise [39]. The ESI tip is grounded and the electrospray field potential is adjusted by controlling the voltage of the concentric nozzle. The mass spectrometer entrance plate is connected to a high voltage power supply to generate and collect ions (counter-electrode in Figure 1). Nitrogen was used as the nebulizing gas (25 psi), heated sheath gas and the drying gas $(4 \mathrm{~L} / \mathrm{min}$, $250{ }^{\circ} \mathrm{C}$ ). The drying gas is delivered around the MS capillary and is orthogonal to the electrospray plume. The commercial AJS source has been modified in order to allow the laser injection into the plume and the epifluorescence measurements. A customized setup was designed to allow for the enrichment of the sheath gas in basic vapors. A bottle containing approximately $2 \mathrm{~mL}$ of the basic reagent at controlled temperature is connected to the nitrogen sheath gas line (Figure 1). Ammonia, triethylamine, and piperidine base solutions were used. Approximately $7 \mathrm{~L} / \mathrm{min}$ of $\mathrm{N}_{2}$ gas is directed across the bottle where head space vapors of the basic reagent can mix with the $\mathrm{N}_{2}$ flow. Nitrogen gas is bubbled into the basic reagent liquid, creating surface turbulence and leading to efficient base desorption. The temperature of the reagent bottle is controlled and can vary from $0{ }^{\circ} \mathrm{C}$ to $40{ }^{\circ} \mathrm{C}$. This $\mathrm{N}_{2}$ /basic vapor was then introduced to the AJS sheath gas heat exchanger. The sheath gas flow rate and temperature were set according to the experiments. The ionization source was operated in negative ion mode with the capillary voltage set at $-2000 \mathrm{~V}$ and the nozzle voltage at $-1200 \mathrm{~V}$ or $-2000 \mathrm{~V}$. The spray current was measured using a picoammeter. In this case, the ESI tip is grounded through the picoammeter (Figure 1). Agilent ChemStation software was used for instrument control, data acquisition and data processing.

Solutions were introduced in the ionization source at $50 \mu \mathrm{L} \min ^{-1}$ flow rate.

\section{Chemicals}

The fluorescent $\mathrm{pH}$ indicator 5 (and 6)-[10-(dimethylamino)3-oxo-3H-benzo[c]xanthenes-7-yl]benzenedicarboxylic acid dye (C.SNARF-1) was purchased from Invitrogen Molecular Probes (Cergy Pontoise, France). Other chemicals: ammonium hydroxide (28\%-30\% in aqueous solution), triethylamine, piperidine, ubiquitin (from bovine erythrocytes), and myoglobin (from equine heart) were obtained from Sigma 
Aldrich (Saint Quentin Fallavier, France). The doubly $\left(\mathrm{A}^{2-}\right.$ ) and singly ( $\mathrm{HA}^{-}$; $\left.\mathrm{pKa} 7.5\right)$ deprotonated species are the fluorescent forms of C.SNARF-1 indicator [40]. All solutions were aqueous and were prepared using Milli-Q water (18.2 M $\Omega . \mathrm{cm}$; Millipore Corporation Billerica, MA, USA). C.SNARF-1 unbuffered solutions were prepared by dilution of a stock solution $(2 \mathrm{mM})$ to a final $50 \mu \mathrm{M}$ concentration. Solutions of $50 \mu \mathrm{M}$ C.SNARF-1 at different $\mathrm{pH}$ values were prepared by adding $1 \mathrm{mM} \mathrm{NaOH}$ prior to final dilution of the stock solution with water. The $\mathrm{pH}$ of solutions was measured using a $211 \mathrm{R} \mathrm{pH}$ meter equipped with a $4 \mathrm{~mm}$-diameter microelectrode (Hanna Instruments, Woonsocket, RI, USA). A calibration curve of the two C.SNARF-1 species fluorescence intensity ratio $\log \left(\mathrm{I}_{\mathrm{A}^{2}} 2-\mathrm{I}_{\mathrm{HA}^{-}}\right)$(where $\mathrm{I}$ is the maximum intensity of each fluorescence band) versus the $\mathrm{pH}$ was obtained from a series of $50 \mu \mathrm{M}$ dye solutions at varying $\mathrm{pH}$ contained in $1-\mathrm{cm}$ quartz cuvette [38]. The potential effect of the temperature on the fluorescence behavior of C.SNARF-1 has been evaluated and was found to be negligible [38].

In order to correlate the $\mathrm{pH}$ in the ESI plume with the MS signal and protein CSD, ubiquitin or myoglobin were added to the sprayed solutions at a $33 \mu \mathrm{M}$ concentration. The protein standards were prepared as directed.

\section{Results and Discussion}

The spraying current is a key parameter in the electrochemical processes involved in electrospray ionization [36, 4143]. Thus, before investigating the $\mathrm{pH}$ profiles of the spray plume with exposure to basic vapors, we first address the effect of basic vapors on the spraying current.

\section{Effect of Basic Vapors on the Spraying Current and Electrochemical Behavior of the Electrospray Interface}

Ions generated during the electrospray process are guided to the counter electrode by the electric field. The current $\mathrm{i}_{\mathrm{ES}}$ generated by the ions on the electrode was measured using the picoammeter and is reported in Table 1 for pure $\mathrm{N}_{2}$ and

Table 1. Estimation and Measurement of $\mathrm{pH}$ Values at the ESI Tip for Different Unbuffered $50 \mu \mathrm{M}$ C.SNARF-1 Solutions $(-2 \mathrm{kV}$ Capillary Voltage, Flow Rate $50 \mu \mathrm{L} / \mathrm{min}$, Nozzle Voltage $-1.2 \mathrm{kV}$, Negative Mode, Sheath Gas Flow Rate $7 \mathrm{~L} / \mathrm{min}$ and Temperature $210^{\circ} \mathrm{C}$ ). Averaged $\mathrm{i}_{\mathrm{ES}}$ was Measured with a Picoamperemeter (Keithley model 6514). See Text for Details on the Calculation

\begin{tabular}{|c|c|c|c|c|}
\hline $\begin{array}{l}\text { Added vapor to } \mathrm{N}_{2} \\
\text { sheath gas }\end{array}$ & $\mathrm{i}_{\mathrm{ES}}(\mathrm{nA})$ & Solution $\mathrm{pH}$ & $\begin{array}{l}\mathrm{pH}_{\mathrm{ESI} \text { tip }} \\
\text { calculated }\end{array}$ & $\begin{array}{l}\mathrm{pH}_{\mathrm{ESI}} \text { tip } \\
\text { measured }\end{array}$ \\
\hline No & 145 & $7.5 \pm 0.01$ & 7.82 & $7.78 \pm 0.05$ \\
\hline Ammonia & 381 & $7.5 \pm 0.01$ & 8.53 & $8.51 \pm 0.09$ \\
\hline Triethylamine & 582 & $7.5 \pm 0.01$ & 9.11 & $9.07 \pm 0.13$ \\
\hline Piperidine & 935 & $7.5 \pm 0.01$ & 9.54 & $9.50 \pm 0.18$ \\
\hline
\end{tabular}

different $\mathrm{N}_{2} /$ basic vapor sheath gas. For pure $\mathrm{N}_{2}$ sheath gas and an unbuffered $50 \mu \mathrm{M}$ C.SNARF-1 aqueous solution $(-2 \mathrm{kV}$ capillary voltage, flow rate $50 \mu \mathrm{L} / \mathrm{min}$, nozzle voltage $-1.2 \mathrm{kV}$, sheath gas flow rate $7 \mathrm{~L} / \mathrm{min}$ and temperature $210^{\circ} \mathrm{C}$ ), a spraying current of $145 \mathrm{nA}$ is measured. Under exposure to basic vapors introduced through the heated sheath gas of the Agilent Jet Stream, the spraying current strongly increases and reaches $935 \mathrm{nA}$ with piperidine basic reagent. The spraying current is dependent on several parameters [44], as shown in equation 1 [45].

$$
i_{E S}=\left(\frac{4 \pi}{\varepsilon}\right)^{3 / 7}(9 \gamma)^{2 / 7} \varepsilon_{0}^{5 / 7} v_{f}^{4 / 7}\left(\sigma E_{C}\right)^{3 / 7}
$$

where $\varepsilon$ and $\varepsilon_{0}$ are respectively the permittivity of the solvent and the permittivity of the vacuum, $\gamma$ is the surface tension of the solvent, $\sigma$ is the electrical conductivity of the solution, $v_{f}$ is the volumetric flow rate and $E_{C}$ is the imposed electric field at capillary tip. The physico-chemical properties (permittivity, surface tension, and conductivity) of the spray composed of water droplets are modified upon exposure to basic vapors due to base incorporation in water. A solubility of $\sim 400 \mathrm{~g} / \mathrm{kg}$ in water at $30{ }^{\circ} \mathrm{C}$ is reported for ammonia. The electric conductivity of the ammonia-water system rapidly increases as soon as ammonia is introduced in water up to a factor 4 for $2-5 \mathrm{~mol} / \mathrm{L}$ of $\mathrm{NH}_{3}$ [46]. The surface tension decreases from 72 dynes/cm (for pure water) to $\sim 55$ dynes/cm (for ammonium hydroxide $30 \%$ in aqueous solution) [47]. Since the dielectric properties of aqueous solutions of ammonia are relatively unaffected by concentration, the solvent permittivity can be treated as a constant [48]. The global effect of these three terms in equation 1 is an increase in the current when $\mathrm{NH}_{3}$ is added to water, which accounts for the high current recorded here. We postulate that similar physicochemical properties are obtained for water droplets seeded with other amines (e.g., triethylamine and piperidine), though solubility and conductivity are available only for triethylamine [49-51].

The spraying current is a key parameter for electrochemical processes occurring in electrospray and plays a central role in the $\mathrm{pH}$ changes observed at the exit of the emitter tip, before the generation of the spray plume [36, 41-43]. Electrochemical events associated with electrospray ionization have been extensively investigated by Van Berkel's group and have been widely referenced in ESI mass spectrometry publications (for a review see References [41, 52]). In particular, the redox reactions that take place in the metal capillary of an electrospray ion source to maintain charge balance alter the composition of the initial solution entering the capillary. It was demonstrated by Van Berkel and coworkers $[36,42]$ that solution $\mathrm{pH}$ may be decreased (or increased) significantly as a result of the electrolytic 
oxidation (or reduction) of water in positive (or negative) ion mode electrospray-mass spectrometry. Relevant reactions for oxidation and reduction of water are $2 \mathrm{H}_{2} \mathrm{O}+4 \mathrm{H}^{+} \rightarrow \mathrm{O}_{2}+4 \mathrm{e}^{-}$and $2 \mathrm{H}_{2} \mathrm{O}+2 \mathrm{e}^{-} \rightarrow 2 \mathrm{OH}^{-}+\mathrm{H}_{2}$. A quantitative estimate of the sprayinduced change in $\mathrm{pH}$ was deduced from the spray current. The relevant concentrations $\left(\left[\mathrm{H}^{+}\right]_{e}\right.$ or $\left.[\mathrm{OH}]_{e}\right)$ for electrolytically generated $\mathrm{H}^{+}$or $\mathrm{OH}^{-}$excess ions can be calculated from the Faraday's law as expressed in equation 2:

$$
\left[\mathrm{H}^{+}\right]_{e} \text { or }\left[\mathrm{OH}^{-}\right]_{e}=\frac{i_{E S}}{F v_{f}}
$$

Where $F$ is the Faraday constant $\left(9.64810^{4}\right.$ C.mol-1), and $v_{f}$ is the volumetric flow rate of solution through the emitter. It should be mentioned that $i_{E S}$ is the nebulizer current measured from the nebulizer to the counter electrode (endcap electrode of the capillary entrance).This current depends on the properties of the electrospray droplets (see equation 1). Thus, alteration of physicochemical properties of the droplets due to the presence of amine basic vapor modifies the spray current without involving a modification of $\mathrm{pH}$ by a partial dissolution of ammonia in water prior to ESI nebulizing. At the ESI tip, the concentration of excess hydroxide ions is mainly due to electrochemical process and can be estimated by equation 2 .

Since C.SNARF-1 is a weak acid with $\mathrm{pKa}=7.5$, it can be expected to react with the electrochemically produced $\mathrm{OH}^{-}$ ions (in the negative mode). The final $\mathrm{pH}$ at the exit of the tip is then estimated, as described in details previously [36] and is given by in equation 3. Where [SNARF] is the initial concentration of C.SNARF-1, $\mathrm{pH}_{\mathrm{in}}$ is the $\mathrm{pH}$ of the initial solution, and $\mathrm{k}_{\mathrm{a}}$ of C.SNARF- $1=10^{-7.5}$ and $\mathrm{k}_{\mathrm{e}}=10^{-14}$. Agreement between the calculated and the measured $\mathrm{pH}$ values is excellent (see Table 1).

The vapor pressure and then the temperature of the bottle containing the reagent are the main parameters that govern the basic reagent concentration in the seeded sheath gas and strongly influence the spray current. Indeed, for ammonia reagent, the ESI current is $331 \mathrm{nA}$ when the bottle is at $0{ }^{\circ} \mathrm{C}$, $381 \mathrm{nA}$ when the bottle is at $25^{\circ} \mathrm{C}$, and $505 \mathrm{nA}$ when the bottle is heated at $40{ }^{\circ} \mathrm{C}$. Thus, the $\mathrm{pH}$ at the exit of the emitter increases from 8.35 to 8.94 when the reagent bottle temperature changes from $0{ }^{\circ} \mathrm{C}$ to $40{ }^{\circ} \mathrm{C}$. The partial vapor pressure increases from 115 Torr at $20{ }^{\circ} \mathrm{C}$ to 338 Torr at $40{ }^{\circ} \mathrm{C}$. The $\mathrm{pH}$ values at the exit of the tip also depends on the nozzle voltage applied on the ESI tip and the sheath gas parameters. Figure S1 in the Supporting Information shows the $\mathrm{pH}$ values along the edge of the plume at different nozzle voltages $(-1.2 \mathrm{kV}$ and $-2.0 \mathrm{kV})$, sheath gas temperatures (SFT), and flow rates (SGF) using triethylamine vapor. The $\mathrm{pH}$ difference between the $\mathrm{pH}$ measured at the exit of the ESI tip and the initial $\mathrm{pH}$ solution is +1.60 at $-1.2 \mathrm{kV}$ [Figure $\mathrm{S} 1(\triangle)$ ], while the $\mathrm{pH}$ difference is +1.85 at $-2.0 \mathrm{kV}$ [Figure S1 (๑)]. A higher nozzle voltage induces an accumulation of charges at the tip and a higher spray current, as predicted by equation $1(725 \mathrm{nA}$ at $-2.0 \mathrm{kV}$ instead of $582 \mathrm{nA}$ at $-1.2 \mathrm{kV}$ ). The $\mathrm{pH}$ at the exit of the emitter tip also slightly depends on the sheath gas parameters (see Figure S1). A higher flow rate induces a higher spray current $(333 \mathrm{nA}$ for $\mathrm{SGF}=3 \mathrm{~L} / \mathrm{min}$ instead of $582 \mathrm{nA}$ for $\mathrm{SGF}=7 \mathrm{~L} / \mathrm{min}$ ).

In summary, AJS source uses heated nitrogen sheath gas to favor ion generation and desolvation [53]. In top of this, the addition of basic vapors in the sheath gas that surrounds the nebulizer spray increases the spray current, which is primarily attributed to an increase in the electrical conductivity of the water-amine enriched solution. The spraying current induces a reduction of water, which generates $\mathrm{OH}^{-}$ions in the negative ion mode. In particular, for $\mathrm{N}_{2}$ sheath gas seeded with piperidine, a spraying current of $\sim 1 \mu \mathrm{A}$ is measured, which induces an increase of $2 \mathrm{pH}$ units at the tip exit.

\section{Profiling the Plume $\mathrm{pH}$}

In this section, we investigate the $\mathrm{pH}$ profiles of the spray plume with exposure to basic vapors. 2D XY maps of the $\mathrm{pH}$ within the ESI plume were obtained from the recorded fluorescence signal of C.SNARF-1 at each point. The $\mathrm{Z}$ axis was centered on the capillary entrance and the dimension of the $X Y$ images was $20 \mathrm{~mm} \times 11 \mathrm{~mm}$ with a step of $500 \mu \mathrm{m}$ in both directions (see picture in Figure 1). The $\mathrm{pH}$ in the ESI plume at each point was determined using the established calibration curve. Figure 2 shows 2D images of the $\mathrm{pH}$ of droplets constituting the plume obtained from a sprayed solution of C.SNARF-1 at $50 \mu \mathrm{M}$ in water at an initial $\mathrm{pH}$ of 7.5 using pure (a) and triethylamine seeded (b) $\mathrm{N}_{2}$ sheath gas in negative ion mode. As previously reported [38], the $\mathrm{pH}$ within the droplets is not homogeneous in the ESI plume. The $\mathrm{pH}$ of the droplets increases as they move down the plume. Moreover, the results of the present study clearly indicate that the $\mathrm{pH}$ of droplets is changed when the ESI plume is exposed to basic vapors. Indeed, for the same solution of C-SNARF-1 in water at an initial $\mathrm{pH}$ of 7.5, the

$$
\begin{aligned}
& p H=
\end{aligned}
$$

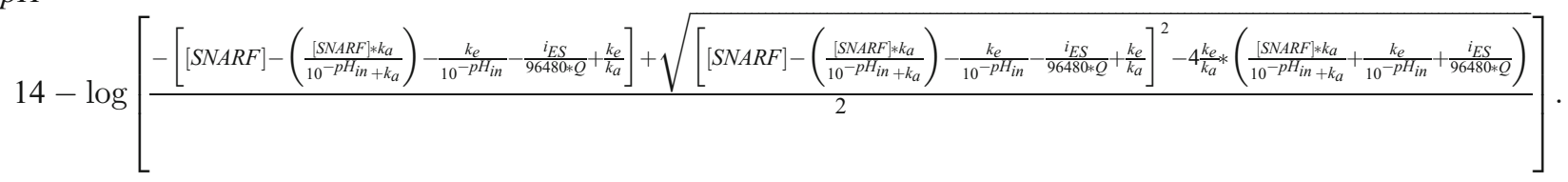



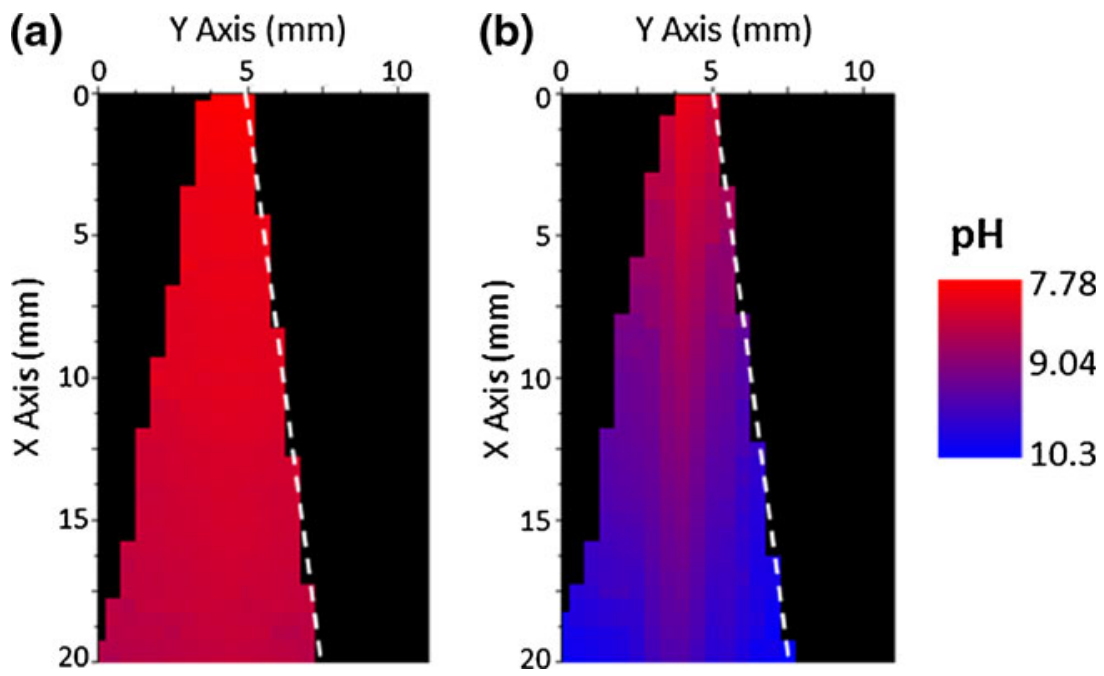

Figure 2. $\mathrm{XY}$ images of the $\mathrm{pH}$ in the plume from the fluorescence of $50 \mu \mathrm{M}$ C.SNARF-1 in water at an initial pH of 7.5 using (a) pure $\mathrm{N}_{2}$ sheath gas and (b) sheath gas seeded with triethylamine vapors. The irradiation time at each step was set to $5 \mathrm{~s}$. The image is constituted of 943 points, and the total acquisition time for an image is $4715 \mathrm{~s}$. The sheath gas parameters were: $\mathrm{SGF}=7 \mathrm{~L} / \mathrm{min}, \mathrm{SGT}=210^{\circ} \mathrm{C}$. The spray was produced in negative ion mode

$\mathrm{pH}$ in the ESI plume is ranging from 7.78 to 8.66 when no vapor is used (Figure $2 \mathrm{a}$ ), while the $\mathrm{pH}$ is ranging from 9.07 to 10.3 when triethylamine vapor is used to seed the sheath gas (Figure 2b). The lateral heterogeneity is also clearly evident when the spray is exposed to triethylamine vapor (Figure $2 b$ ). The $\mathrm{pH}$ is higher at both edges of the spray plume than at the center.

The same fluorescent measurements were made using ammonia and piperidine as reagent for enrichment of the sheath gas. $\mathrm{pH}$ values along the edge of the plume (see dashed line in Figure 2) obtained with no vapor and different basic vapor exposures are plotted in Figure 3. The $\mathrm{pH}$ values were projected onto the $\mathrm{X}$ axis. The error bars on the $\mathrm{pH}$ values depends on the accuracy of the fluorescence measurements.
This error can be estimated by calculating a standard deviation based on three replicates of the fluorescence signal measurement at each point. This error ranges from \pm 0.01 to $\pm 0.25 \mathrm{pH}$ units (note that the precision on the $\mathrm{pH}$ values of the initial solutions with the commercial $\mathrm{pH}$ meter is \pm 0.01$)$. The large errors observed for the highest $\mathrm{pH}$ values reflect measurements beyond the optimum $\mathrm{pH}$ range of the C.SNARF-1 dye.

Evolution of the $\mathrm{pH}$ along the edge of the plume using different seeded sheath gas (see Figure 3) is discussed in details below. As already discussed in the previous section, because of an electrochemical effect at the electrospray interface, the $\mathrm{pH}$ measured at the exit of the emitter tip $(\mathrm{X}=$ $0 \mathrm{~mm}$ ) is higher than the initial $\mathrm{pH}$ of the presprayed

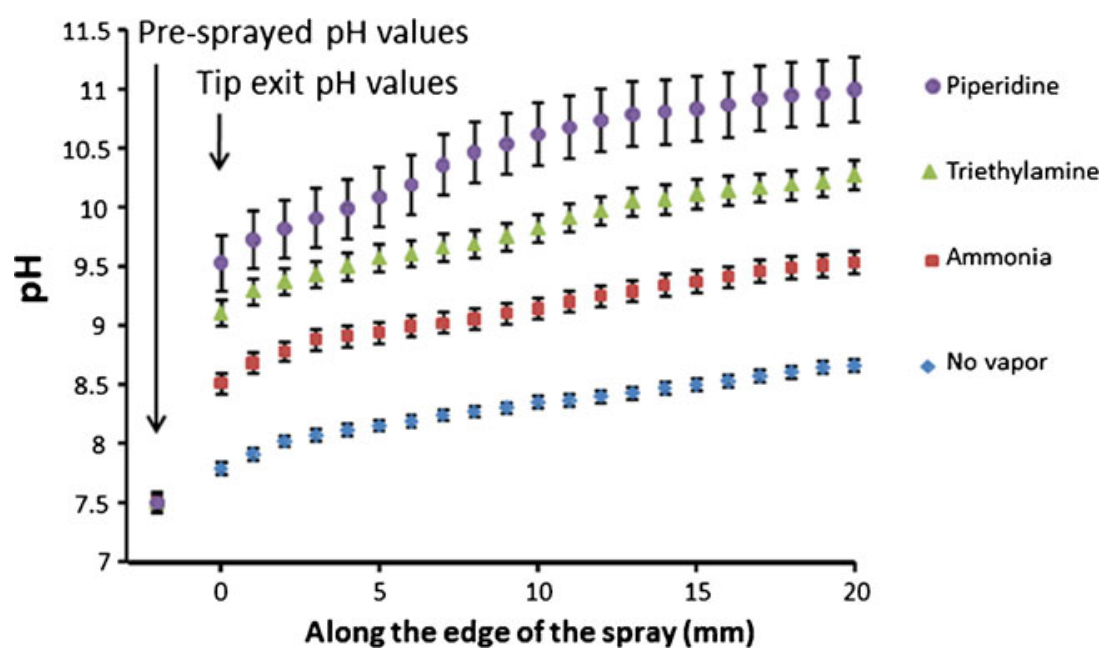

Figure 3. Plots of the $\mathrm{pH}$ values determined from the fluorescence spectra of $50 \mu \mathrm{M} \mathrm{C.SNARF-1}$ in water along the edge of the spray plume (dashed line in Figure 2). The left hand point reports the $\mathrm{pH}$ of the initial solution prior to spraying, which is 7.5 for all the plots. The ionization parameters were: SGF $=7 \mathrm{~L} / \mathrm{min}, \mathrm{SGT}=210^{\circ} \mathrm{C}$. The sheath gas was seeded with $(\bigcirc)$ no vapor, ( ammonia vapor, $(\triangle)$ triethylamine vapor, and (O) piperidine vapor 
solutions and depends on the basic seeded sheath gas. Then along the plume, the $\mathrm{pH}$ of the droplets increases (Figure 3). The increase without basic exposure is consistent with the intuitive expectation that the $\mathrm{pH}$ of a basic solution should increase as the volume of droplets decreases and the basic species become more concentrated due to solvent evaporation [38]. The increase in $\mathrm{OH}^{-}$concentration is related to the decrease in the droplet volume, attributable to evaporation along the spray plume. The evaporation rate follows the surface evaporation limit law, which leads to a simple dependence of the droplet radius on time $\mathrm{t}[55,56]\left(R=R_{0}-9.9610^{-5} \mathrm{t}\right.$, for water droplets at $300 \mathrm{~K}$ ). Assuming an initial droplet diameter of $3 \mu \mathrm{m}$ [38], and a droplet velocity of $\sim 1 \mathrm{~m} / \mathrm{s}$ [54], evaporation of droplets leads to $\sim 27$-fold decrease in the volume at $20 \mathrm{~mm}$. Moreover, the $\mathrm{pH}$ evolution in the plume is different when the sheath gas is seeded with a base. As shown in Figure 2, the $\mathrm{pH}$ is higher at the edges of the spray plume where the droplets are more exposed to the seeded sheath gas. The difference in $\mathrm{pH}$ along the edge of the plume (dashed line in Figure 2) is $\Delta=$ +0.87 when no vapor is used, while $\Delta=+1.02, \Delta=+1.17$ and $\Delta$ $=+1.47$ when ammonia, triethylamine, and piperidine vapor are used to seed the sheath gas, respectively. With the introduction of increasingly strong basic vapors for the enrichment of the sheath gas, the $\mathrm{pH}$ at the edge of the plume increases. The exposure of droplets to the basic vapors yields to incorporation of bases in the droplets and $\mathrm{pH}$ modification, which depends on the pKa of the basic reagent. The $\mathrm{pH}$ in the droplets at the edges of the spray increases when the concentration of basic reagent is increased according to equation 4 (see Figure S1).

$$
p H=p K_{b}+\log \left\{\left(C_{0 b} V_{b}-C_{0 a} V_{a}\right) / C_{0 a} V_{a}\right\}
$$

where $p K_{b}$ is the pKa value of the base [ammonia (9.25), triethylamine (10.72), and piperidine (11.12)] [57], $C_{0 b}, C_{0 a}$ and $V_{b}, V_{a}$ are the concentration and volume of the added base and the acid dye C.SNARF-1. In order to confirm the role of the seeded sheath gas on the $\mathrm{pH}$ evolution of the droplets along the spray plume, the $\mathrm{pH}$ evolution from a sprayed solution of initial $\mathrm{pH} 7.5$ exposed to triethylamine vapors has been compared with the one from a sprayed solution of initial $\mathrm{pH} 8.75$ using no vapor (Figure 4). These two solutions have the same $\mathrm{pH}(\mathrm{pH}=9)$ at the exit of the emitter tip. In case of the $\mathrm{pH} 8.75$ initial solution sprayed with pure sheath gas, the $\mathrm{pH}$ in the plume increases only due to the solvent evaporation [38]. The $\mathrm{pH}$ increase along the edge of the spray is higher when triethylamine is used to seed the sheath gas. Indeed, the difference in $\mathrm{pH}$ along the edge of the plume (dashed line in Figure 2) is $\Delta=+0.87$ when no vapor is used, while $\Delta=+1.17$ when the plume is exposed to triethylamine vapors. Though the $\mathrm{pH}$ increase in the ESI plume is more efficient using basic seeded sheath gas, incorporation of basic vapors in the spray droplets accounts for only $35 \%$ of the increase, the major effect being due to the solvent evaporation process. A more significant finding is that, mainly due to electrochemical effects, higher $\mathrm{pH}$ values can be obtained with a less basic initial solution $(\mathrm{pH}$ 7.5) sprayed using seeded sheath gas than with a more basic initial solution $(\mathrm{pH} 8.75)$ sprayed with pure sheath gas.

\section{Correlation Between the $\mathrm{pH}$ in the ESI Plume and the MS Signal}

The $\mathrm{pH}$ evolution in the ESI plume obtained using pure and basic seeded sheath gases was correlated with the evolution of the charge state distribution (CSD) observed in MS spectra of proteins. Protein CSDs are known to be related to conformational states, with more unfolded conformations resulting in much higher observed charge states compared with more folded conformations [3, 58]. Less structured molecules can accommodate more charges during the ion desolvation phase. Ubiquitin is a 76-residue protein with 12

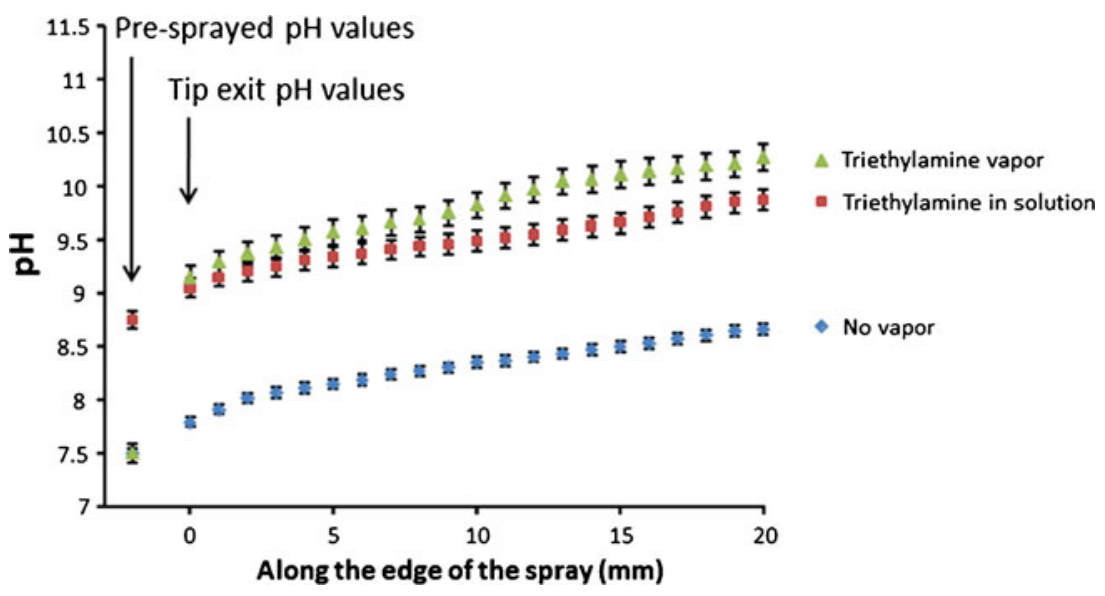

Figure 4. Plots of the $\mathrm{pH}$ values determined from the fluorescence spectra of $50 \mu \mathrm{M} \mathrm{C.SNARF-1}$ in water along the edge of the spray plume (dashed line in Figure 2). Initial pH values: $(\triangle)$ and $(\Lambda), 7.5$ and $(\square), 8.75$ (adjusted in solution with triethylamine). The sheath gas was seeded with $(\circlearrowleft)$ and $(\square)$ no vapor and $(\Lambda)$ triethylamine vapor. The ionization parameters were: SGF= $7 \mathrm{~L} / \mathrm{min}, \mathrm{SGT}=210^{\circ} \mathrm{C}$ 
basic and 11 acid residues and an isoelectric point of 5.2 [59]. When an aqueous solution (initial $\mathrm{pH}$ 7.5) of ubiquitin was analyzed by ESI-MS with no vapor in the sheath gas (Figure 5a), the $[\mathrm{M}-4 \mathrm{H}]^{4-}$ and $[\mathrm{M}-5 \mathrm{H}]^{5-}$ anions are detected with a weak intensity, indicating the native structure of the protein. Spraying the same ubiquitin solution in negative ion mode using triethylamine vapor to seed the sheath gas causes an increase of two orders of magnitude of the total ion count and a shift in the CSD to higher charge states (Figure 5c). For comparison, the MS spectrum of ubiquitin in water at an initial $\mathrm{pH}$ of 8.75 (adjusted with triethylamine) using no vapor in the sheath gas is shown in

(a)

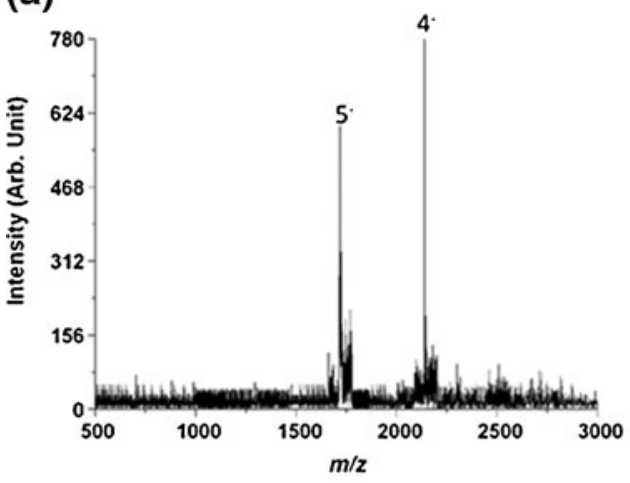

(b)

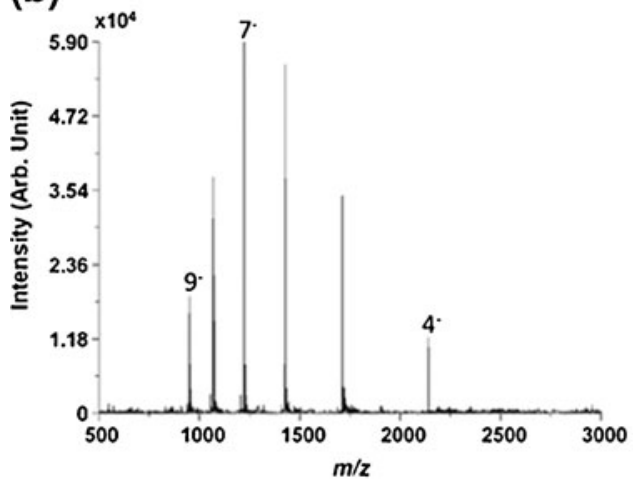

(c)

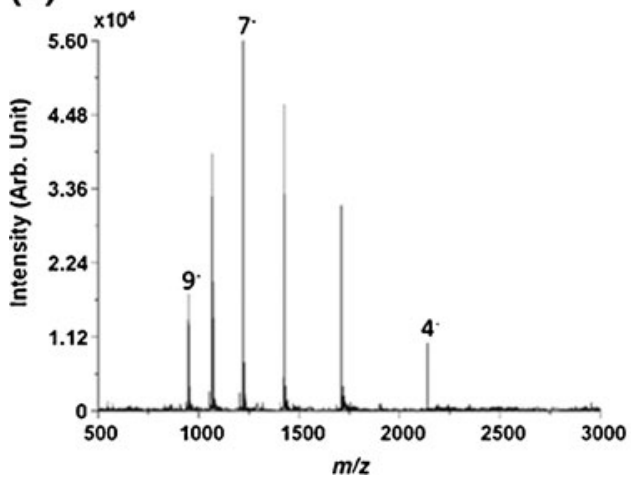

Figure 5b. Note that MS spectrum in Figure 5c, compared with the one shown in Figure 5b, has been obtained without alteration of the initial solution used in Figure 5a. The average charge state of ubiquitin, $Z_{n}$, can be calculated from the observed distribution using the formula:

$$
Z_{n}=\frac{\sum N_{i} z_{i}}{\sum N_{i}}
$$

$\mathrm{N}_{\mathrm{i}}$ corresponds to the number of ions of charge state $\mathrm{z}_{\mathrm{i}}$. The average charge states calculated from MS spectra in Figure 5 are presented in Table 2. The average charge state

\section{(d)}

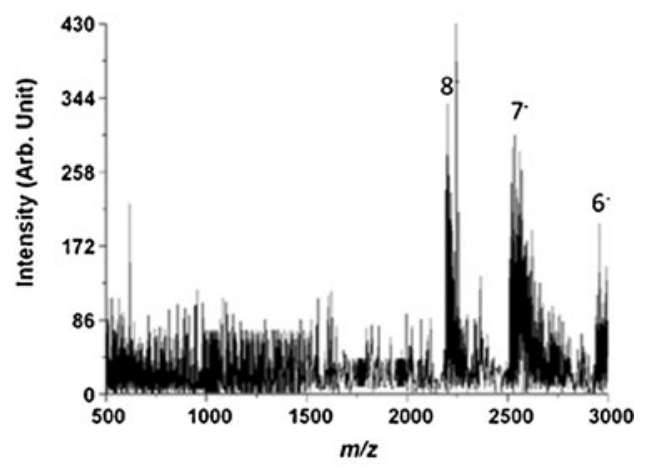

(e)

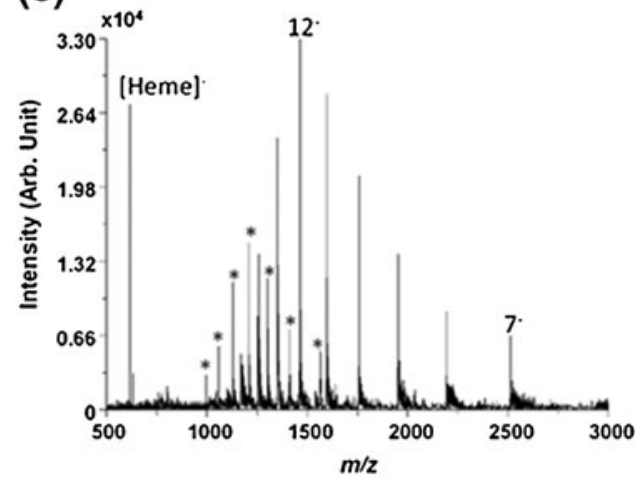

(f)

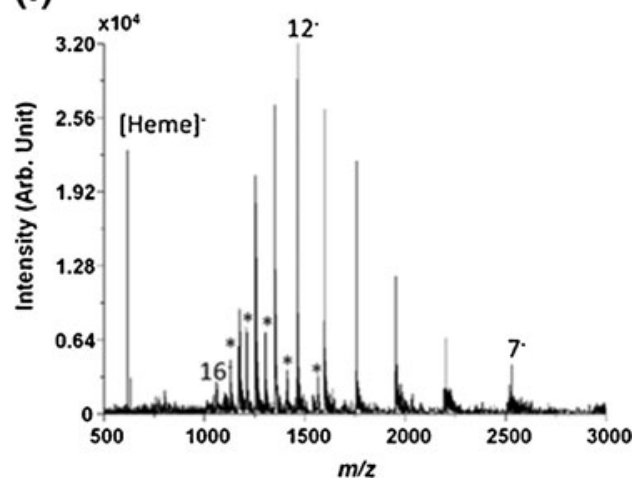

Figure 5. Negative ESI-MS spectra of $33 \mu \mathrm{M}$ of ubiquitin (a)-(c) and myoglobin (d)-(f) in water (with $50 \mu \mathrm{M}$ of C.SNARF-1) with (a) and (d) no vapor and an initial pH of 7.5, (b) and (e) no vapor and an initial pH of 8.75 (adjusted in solution with triethylamine), and (c) and (f) triethylamine vapor and an initial pH of 7.5. Sheath gas parameters were: SGF=7 L/min, SGT= $210^{\circ} \mathrm{C}$. *Indicates the apo form of myoglobin 
Table 2. Calculated Average Charge State $Z_{n}$ of Ubiquitin and (holo-) Myoglobin in the Negative Ion mode from the CSD Observed for Water Solutions at Initial $\mathrm{pH}$ of 7.50 and 8.75 with or without Triethylamine Vapor. See Text for Details on the Calculation

\begin{tabular}{|c|c|c|c|c|}
\hline Protein & Initial solution $\mathrm{pH}$ & Added vapor & $\begin{array}{l}\mathrm{pH} \text { at } \mathrm{X}= \\
13 \mathrm{~mm} \text { and } \\
\mathrm{Y}=7 \mathrm{~mm}\end{array}$ & $\begin{array}{l}Z_{\mathrm{n}} \\
\text { calculated }\end{array}$ \\
\hline Ubiquitin & 7.50 & No & 8.29 & -4.4 \\
\hline Ubiquitin & 8.75 & No & 9.73 & -6.4 \\
\hline Ubiquitin & 7.50 & Triethylamine & 10.09 & -6.7 \\
\hline Myoglobin & 7.50 & No & 8.30 & -7.2 \\
\hline Myoglobin & 8.75 & No & 9.75 & -11.2 \\
\hline Myoglobin & 7.50 & Triethylamine & 10.10 & -11.6 \\
\hline
\end{tabular}

increases with the use of basic sheath gas. Similar results were observed previously using leak-in of basic vapors during the ESI process [34]. Also, similar electrochemically induced $\mathrm{pH}$ changes (using an "ESI loop circuit") resulting in protein unfolding in the ion source of an electrospray mass spectrometer have been reported by Konermann et al. [60]. Our results suggest that protein unfolding begins immediately at the tip exit where drastic $\mathrm{pH}$ changes are observed due to electrochemical effects.

The same experiments were done with myoglobin in order to study the influence of the seeded sheath gas on conformationally dependent noncovalent interactions. Myoglobin is a 153-residue protein with an isoelectric point of 7.2 [61]. The native form of myoglobin (i.e., holomyoglobin) in water at $\mathrm{pH}$ 7.5 in negative ion mode using pure sheath gas is detected as $8,-7$, and $-6[\mathrm{M}-\mathrm{nH}]^{\mathrm{n}-}$ anions (Figure $5 \mathrm{~d}$ ). In this case, the heme group is noncovalently bound to the protein $[62,63]$. After electrospraying the same solution using sheath gas seeded with triethylamine, the signal is multiplied by two orders of magnitude and the CSD is drastically shifted to more negative charges $\left(Z_{n}=-11.6\right.$ instead of -7.2$)$ with approximately $85 \%$ of peaks corresponding to holomyoglobin (Figure $5 \mathrm{f}$ ). A peak corresponding to [heme $]^{-}$was also observed. The increase in $\mathrm{pH}$ in the ESI plume due to the basic vapors induces the denaturation of the myoglobin protein and the removing of some heme groups. For comparison, the MS spectrum of myoglobin in water at an initial $\mathrm{pH}$ of 8.75 (adjusted with triethylamine) using no vapor in the sheath gas is shown in Figure 5e. In this case, $Z_{n}=-11.2$ but more interestingly, only $73 \%$ of peaks corresponds to holomyoglobin. The apomyoglobin form is detected with a CSD from -11 to -17 . Indeed, adding denaturing reagent to the myoglobin sample in the condensed phase results in the heme group falling off almost immediately [64]. An important finding of this work is that ESI-MS with seeded sheath gas preserves more of the noncovalent interactions while shifting CSD, in agreement with previous studies [34].

\section{Conclusion}

Using a specially designed apparatus, we successfully enriched the nitrogen sheath gas of an Agilent Jet Stream
ESI source with basic vapors in negative electrospray mode to shift the CSD of ubiquitin and myoglobin proteins. An optical setup, using laser-induced fluorescence of a $\mathrm{pH}$-chromic dye, permitted the $\mathrm{pH}$ profiling of droplets as they evaporated in the electrospray plume to provide a better understanding of the correlation between $\mathrm{pH}$ and the charge state distribution of proteins. The most significant result is that $\mathrm{pH}$ changes due to the basic seeded sheath gas mainly occur at the exit of the ESI tip, and is mainly due to electrochemical effects. When the nitrogen sheath gas, which surrounds the nebulizer spray in the AJS source, is enriched with basic vapors, the spraying current is increased. The reduction of water induces generation of electrolytically produced $\mathrm{OH}^{-}$ions, and increases the $\mathrm{pH}$ at the ESI tip exit. For example, when $\mathrm{N}_{2}$ sheath gas is seeded with piperidine, a spraying current of $\sim 1 \mu \mathrm{A}$ is measured, which induces a $\mathrm{pH}$ increase of $2 \mathrm{pH}$ units at the tip exit when spraying an unbuffered $50 \mu \mathrm{M}$ C.SNARF-1 solution at $\mathrm{pH}$ 7.5. Along the electrospray plume, the $\mathrm{pH}$ of the droplets increases, which is consistent with the intuitive expectation that the $\mathrm{pH}$ of a basic solution should increase as the volume of droplets decreases and the basic species become more concentrated due to the solvent evaporation. The $\mathrm{pH}$ of droplets increase along the plume also depends on the basic vapors used for the nitrogen sheath gas enrichment. In this case, the $\mathrm{pH}$ increase is due to both evaporation and incorporation of basic reagents in droplets. In summary, the addition of bases into the vapor has two effects: (1) at the tip exit, the $\mathrm{pH}$ strongly increases due to electrochemical effects (resulting from an increase in the spray current upon base addition). (2) Along the plume, the $\mathrm{pH}$ further increases due to partial dissolution of bases in droplets.

The $\mathrm{pH}$ in the ESI plume obtained using pure and basic seeded sheath gas was correlated to the evolution of the CSD observed in the mass spectra of proteins in negative ion mode. A strong increase in the ion count and a shift in the CSD are observed upon sheath gas seeding with basic vapors. Our results suggest that the protein unfolding and charging begin at the exit of the ESI tip due to the strong increase in $\mathrm{pH}$ at the tip exit. High protein ion signal and charge states, usually obtained with basic initial solutions (respectively acidic solutions for positive ESI), can be obtained using native solution conditions by seeding the heated sheath gas with basic (resp. acidic) vapors, in the negative ion mode. By taking advantage of the Agilent Jet Stream source geometry, this vapor introduction technique can be used in liquid chromatography mass spectrometry (LC-MS) coupling to combine efficient LC solvent conditions with high MS signal. Another advantage of this method is the ability to control the CSD without affecting protein structures in the bulk solution. This has many potential applications in native mass spectrometry, including the study of biomolecular complexes. 


\section{Acknowledgments}

The authors acknowledge support for this work by Agilent Technologies with an award through Agilent's Application and Core Technology University Research Program (grant ID 2243). The authors thank David Lascoux for help in initiating the project. Jacques Maurelli is acknowledged for his invaluable technical assistance.

\section{Supporting Information}

Additional supporting information may be found free of charge in the online version of this article: Plots of the $\mathrm{pH}$ values determined from the fluorescence spectra of $50 \mu \mathrm{M}$ C.SNARF-1 in water along the edge of the spray plume with the sheath gas seeded with triethylamine at different temperatures and flow rates and nozzle voltages. Vapor pressure at $25^{\circ} \mathrm{C}$ of the three different bases used in this work.

\section{References}

1. Fenn, J.B., Mann, M., Meng, C.K., Wong, S.F., Whitehouse, C.M.: Electrospray ionization for mass spectrometry of large biomolecules. Science 246, 64 (1989)

2. Mann, M., Meng, C.K., Fenn, J.B.: Interpreting mass spectra of multiply charged ions. Anal. Chem. 61, 1702-1708 (1989)

3. Chowdhury, S.K., Katta, V., Chait, B.T.: Probing conformational changes in proteins by mass spectrometry. J. Am. Chem. Soc. 112, 9012-9013 (1990)

4. Konermann, L., Douglas, D.J.: Equilibrium unfolding of proteins monitored by electrospray ionization mass spectrometry: Distinguishing two-state from multi-state transitions. Rapid Commun. Mass Spectrom. 12, 435-442 (1998)

5. Wang, G., Cole, R.B.: Disparity between solution phase equilibria and charge state distributions in positive ion electrospray mass spectrometry. Org. Mass Spectrom. 29, 419-427 (1994)

6. Le Blanc, J.C.Y., Wang, J., Guevremont, R., Siu, K.W.M.: Electrospray mass spectra of protein cations formed in basic solutions. Org. Mass Spectrom. 29, 587-593 (1994)

7. Chillier, X.F.D., Monnier, A., Bill, H., Gulacar, F., Buchs, A., McLuckey, S.A., Van Berkel, G.J.: A mass spectrometry and optical spectroscopy investigation of gas-phase ion formation in electrospray. Rapid Commun. Mass Spectrom. 10, 299 (1996)

8. Iavarone, A.T., Jurchen, J.C., Williams, E.R.: Effects of solvent on the maximum charge state and charge state distribution of protein ions produced by electrospray ionization. J. Am. Soc. Mass Spectrom. 11, 976-985 (2000)

9. Schnier, P.D., Gross, D.S., Williams, E.R.: On the maximum charge state and proton transfer reactivity of peptide and protein ions formed by electrospray ionization. J. Am. Soc. Mass Spectrom. 6, 1086-1097 (1995)

10. Mirza, U., Chait, B.: Effects of anions on the positive-ion electrosprayionization mass-spectra of peptides and proteins. Anal. Chem. 66, 2898 (1994)

11. Page, J., Kelly, R., Tang, K., Smith, R.: Ionization and transmission efficiency in an electrospray ionization-mass spectrometry interface. $J$. Am. Soc. Mass Spectrom. 18, 1582-1590 (2007)

12. Williams, E.R.: Proton transfer reactivity of large multiply charged ions. J. Mass Spectrom. 31, 831-842 (1996)

13. Iavarone, A.T., Williams, E.R.: Mechanism of charging and supercharging molecules in electrospray ionization. J. Am. Chem. Soc. 125, 2319-2327 (2003)

14. Reid, G.E., McLuckey, S.A.: Top down protein characterization via tandem mass spectrometry. J. Mass Spectrom. 37, 663-675 (2002)

15. Cui, W., Rohrs, H.W., Gross, M.L.: Top down mass spectrometry: Recent developments, applications, and perspectives. Analyst 136, 3854-3864 (2011)

16. Frey, B.L., Krusemark, C.J., Ledvina, A.R., Coon, J.J., Belshaw, P.J., Smith, L.M.: Ion-ion reactions with fixed-charge modified proteins to produce ions in a single, very high charge state. Int. J. Mass Spectrom. 276, 136 (2008)
17. Iavarone, A.T., Jurchen, J.C., Williams, E.R.: Supercharged protein and peptide ions formed by electrospray ionization. Anal. Chem. 73, 14551460 (2001)

18. Iavarone, A.T., Williams, E.R.: Supercharging in electrospray ionization: effects on signal and charge. Int. J. Mass Spectrom. 219, 63-72 (2002)

19. Lomeli, S., Yin, S., Ogorzalek Loo, R., Loo, J.: Increasing charge while preserving noncovalent protein complexes for ESI-MS. J. Am. Soc. Mass Spectrom. 20, 593-596 (2009)

20. Lomeli, S., Peng, I., Yin, S., Ogorzalek Loo, R., Loo, J.: New reagents for increasing ESI multiple charging of proteins and protein complexes. J. Am. Soc. Mass Spectrom. 21, 127-131 (2010)

21. Ganisl, B., Taucher, M., Riml, C., Breuker, K.: Charge as you like! Efficient manipulation of negative ion net charge in electrospray ionization of proteins and nucleic acids. Eur. J. Mass Spectrom. 17, 333 (2011)

22. Zhao, C., Wood, T., Bruckenstein, S.: Shifts in protein charge state distributions with varying redox reagents in nanoelectrospray triple quadrupole mass spectrometry. J. Am. Soc. Mass Spectrom. 16, 409416 (2005)

23. Scalf, M., Westphall, M.S., Krause, J., Kaufman, S.L., Smith, L.M.: Controlling charge states of large ions. Science 283, 194-197 (1999)

24. Stephenson, J.L., McLuckey, S.A.: Ion/ion reactions in the gas phase: tranfer Proton transfer reactions involving multiply-charged proteins. $J$. Am. Chem. Soc. 118, 7390-7397 (1996)

25. McLuckey, S.A., Van Berkel, G.J., Glish, G.L.: Reactions of dimethylamine with multiply charged ions of cytochrome c. J. Am. Chem. Soc. 112, 5668-5670 (1990)

26. Loo, R.R.O., Loo, J.A., Udseth, H.R., Fulton, J.L., Smith, R.D.: Protein structural effects in gas phase ion/molecule reactions with diethylamine. Rapid Commun. Mass Spectrom. 6, 159-165 (1992)

27. Hunter, A.P., Severs, J.C., Harris, F.M., Games, D.E.: Proton transfer reactions of mass-selected multiply charged ions. Rapid Commun. Mass Spectrom. 8, 417-422 (1994)

28. Chen, H., Venter, A., Cooks, R.G. Extractive electrospray ionization for direct analysis of undiluted urine, milk, and other complex mixtures without sample preparation. Chem. Commun. 2042-2044 (2006)

29. Yang, S.H., Wijeratne, A.B., Li, L., Edwards, B.L., Schug, K.A.: Manipulation of protein charge states through continuous flowextractive desorption electrospray ionization: A new ambient ionization technique. Anal. Chem. 83, 643-647 (2010)

30. Peng, Y., Zhang, S., Gong, X., Ma, X., Yang, C., Zhang, X.: Controlling charge states of peptides through inductive electrospray ionization mass spectrometry. Anal. Chem. 83, 8863-8866 (2011)

31. Bagal, D., Zhang, H., Schnier, P.D.: Gas-phase proton-transfer chemistry coupled with TOF mass spectrometry and ion mobility-MS for the facile analysis of poly(ethylene glycols) and PEGylated polypeptide conjugates. Anal. Chem. 80, 2408-2418 (2008)

32. Kharlamova, A., DeMuth, J., McLuckey, S.: Vapor treatment of electrospray droplets: Evidence for the folding of initially denatured proteins on the sub-millisecond time-scale. J. Am. Soc. Mass Spectrom. 23, 88-101 (2012)

33. Kharlamova, A., Prentice, B.M., Huang, T.Y., McLuckey, S.A.: Electrospray droplet exposure to gaseous acids for the manipulation of protein charge state distributions. Anal. Chem. 82, 7422-7429 (2010)

34. Kharlamova, A., McLuckey, S.A.: Negative electrospray droplet exposure to gaseous bases for the manipulation of protein charge state distributions. Anal. Chem. 83, 431-437 (2011)

35. Zhou, S., Prebyl, B.S., Cook, K.D.: Profiling $\mathrm{pH}$ changes in the electrospray plume. Anal. Chem. 74, 4885 (2002)

36. Zhou, S., Edwards, A.G., Cook, K.D., Van Berkel, G.J.: Investigation of the electrospray plume by laser-induced fluorescence spectroscopy. Anal. Chem. 71, 769 (1999)

37. Wang, R., Zenobi, R.: Evolution of the solvent polarity in an electrospray plume. J. Am. Soc. Mass Spectrom. 21, 378 (2010)

38. Girod, M., Dagany, X., Antoine, R., Dugourd, P.: Relation between charge state distributions of peptide anions and $\mathrm{pH}$ changes in the electrospray plume. A mass spectrometry and optical spectroscopy investigation. Int. J. Mass Spectrom. 308, 41-48 (2011)

39. Girod, M., Dagany, X., Boutou, V., Broyer, M., Antoine, R., Dugourd, P., Mordehai, A., Love, C., Werlich, M., Fjeldsted, J., Stafford, G.: Profiling an electrospray plume by laser-induced fluorescence and Fraunhofer diffraction combined to mass spectrometry: Influence of size and composition of droplets on charge-state distributions of electro- 
sprayed proteins. Phys. Chem. Chem. Phys. (2012). doi:10.1039/ C1032CP23341J

40. Whitaker, J.E., Hauglan, R.P., Prendergast, F.G.: Spectral and photophysical studies of benzo[c]xanthene dyes: Dual emission $\mathrm{pH}$ sensors. Anal. Biochem. 194, 330 Fraunhofer diffraction 344 (1991)

41. Van Berkel, G.J., Kertesz, V.: Using the electrochemistry of the electrospray ion source. Anal. Chem. 79, 5510 (2007)

42. Van Berkel, G.J., Zhou, F., Aronson, J.T.: Changes in bulk solution $\mathrm{pH}$ caused by the inherent controlled-current electrolytic process of an electrospray ion source. Int. J. Mass Spectrom. Ion Process. 162, 55-67 (1997)

43. Rohner, T.C., Lion, N., Girault, H.H.: Electrochemical and theoretical aspects of electrospray ionization. Phys. Chem. Chem. Phys. 6, 3056 (2004)

44. Pfeifer, R.J., Hendrick, C.D.: Parametric studies of electrohydrodynamic spraying. AIAA J. 6, 496 (1968)

45. Ikonomou, M.G., Blades, A.T., Kebarle, P.: Investigations of the electrospray interface for liquid chromatography/mass spectrometry. Anal. Chem. 62, 957-967 (1990)

46. Shcherbakov, V.V., Artemkina, Y.M., Ponomareva, T.N., Kirillov, A.D.: Electrical conductivity of the ammonia-water zystem. Russ. J. Inorg. Chem. 54, 277 (2009)

47. King, H.H., Hall, J.L., Ware, G.C.: A study of the density, surface tension, and adsorption in the water-ammonia system at $20 / \mathrm{C}$. Am. Chem. Soc. 52, 5130 (1930)

48. Potapov, A.A., Parkhomenko, I.Y.: Dielectric properties of solutions isomorphous with water. Russ. J. Gen. Chem. 75, 34 (2005)

49. Stephenson, R.M.: Mutual solubility of water and pyridine derivatives. J. Chem. Eng. Data 38, 428-431 (1993)

50. Ablard, J.E., McKinney, D.S., Warner, J.C.: The conductance, dissociation constant, and heat of dissociation of triethylamine in water. J. Am. Chem. Soc. 62, 2181-2183 (1940)

51. Campbell, A.N., Lam, S.-Y.: The Dissociation constants and conductivities of mono-, di-, and triethylamine in aqueous solution. Can. J. Chem. 51, 551-555 (1973)
52. Van Berkel, G.J.: The electrolytic nature of electrospray. In: Cole, R. (ed.) Electrospray Ionization Mass Spectrometry: Fundamentals, Instrumentation and Applications, John Wiley, NY (1997)

53. Mordehai, A.: ESI technology with thermal gradient focusing - theoretical and practical aspects. Proceedings of the 57th ASMS Conference on Mass Spectrometry and Allied Topics, Philadelphia, PA, (2009)

54. Nemes, P., Marginean, I., Vertes, A.: Spraying mode effect on Droplet formation and ion chemistry in electrosprays. Anal. Chem. 79, 3105 (2007)

55. Kebarle, P., Tang, L.: From ions in solution to ions in the gas phasethe mechanism of electrospray mass spectrometry. Anal. Chem. 65, 972A (1993)

56. Taflin, D.C., Ward, T.L., Davis, E.J.: Electrified droplet fission and the Rayleigh limit. Langmuir 5, 376 (1989)

57. Lide, D.R.: CRC Handbook of Chemistry and Physics, 70th edn. CRC Press, Boca Raton (1990)

58. Kaltashov, I.A., Eyles, S.J.: Studies of biomolecular conformations and conformational dynamics by mass spectrometry. Mass Spectrom. Rev. 21, 37-71 (2002)

59. Vijay-Kumar, S., Bugg, C.E., Cook, W.J.: Structure of ubiquitin refined

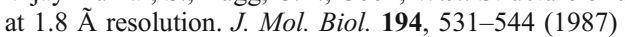

60. Konermann, L., Silva, E.A., Sogbein, O.F.: Electrochemically induced $\mathrm{pH}$ changes resulting in protein unfolding in the ion source of an electrospray mass spectrometer. Anal. Chem. 73, 4836-4844 (2001)

61. Antonini, E., Brunori, M.: Hemoglobin and myoglobin in their reaction with ligands. North-Holland Publishing Co, Amsterdam (1971)

62. Li, Y.T., Hsieh, Y.L., Henion, J.D., Ganem, B.: Studies on heme binding in myoglobin, hemoglobin, and cytochrome $c$ by ion spray mass spectrometry. J. Am. Soc. Mass Spectrom. 4, 631-637 (1993)

63. Katta, V., Chait, B.T.: Observation of the heme-goblin complex in native myoglobin by electrospray ionization mass spectrometry. $\mathrm{J}$. Am. Chem. Soc. 113, 8534-8535 (1991)

64. Sogbein, O.O., Simmons, D.A., Konermann, L.: Effects of $\mathrm{pH}$ on the kinetic reaction mechanism of myoglobin unfolding studied by timeresolved electrospray ionization mass spectrometry. J. Am. Soc. Mass Spectrom. 11, 312-319 (2000) 